\title{
Transposition
}

Musique et Sciences Sociales

9| 2021

Musique et sexualité

\section{Robert Fink, Melinda Latour, Zachary Wallmark (eds.), The Relentless Pursuit of Tone. Timbre in Popular Music}

New York, Oxford University Press, 2018

Martin Pfleiderer

\section{OpenEdition}

\section{Journals}

\section{Electronic version}

URL: http://journals.openedition.org/transposition/5712

DOI: 10.4000/transposition.5712

ISSN: $2110-6134$

Publisher

CRAL - Centre de recherche sur les arts et le langage

\section{Electronic reference}

Martin Pfleiderer, "Robert Fink, Melinda Latour, Zachary Wallmark (eds.), The Relentless Pursuit of Tone Timbre in Popular Music", Transposition [Online], 9 | 2021, Online since 15 December 2020, connection on 23 April 2021. URL: http://journals.openedition.org/transposition/5712 ; DOI: https://doi.org/ 10.4000/transposition. 5712

This text was automatically generated on 23 April 2021

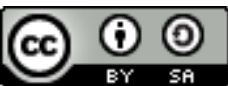

La revue Transposition est mise à disposition selon les termes de la Licence Creative Commons Attribution - Partage dans les Mêmes Conditions 4.0 International. 


\title{
Robert Fink, Melinda Latour, Zachary Wallmark (eds.), The Relentless Pursuit of Tone. Timbre in Popular Music
}

\author{
New York, Oxford University Press, 2018
}

\section{Martin Pfleiderer}

\section{REFERENCES}

Robert Fink, Melinda Latour, Zachary Wallmark (eds.), The Relentless Pursuit of Tone.

Timbre in Popular Music, New York, Oxford University Press, 2018, 386 p.

1 Many myths, ideologies and aspirations go along with the concept of 'tone'- or 'sound' as favored outside the Anglophonic world. Time and again, the 'tone' of a certain genre of popular music, a certain musician or a specific instrument is claimed to be the key for a deep experience and understanding of the music. Moreover, 'tone', 'sound' or 'timbre' are labels for a special quality that is the alleged essence of the music - and which could be achieved by buying certain musical instruments or electronic devices, or by tuning oneself in on a certain music world and the sounds it affords. In popular music research a focus on timbre, tone and sound often marks a difference to conventional musicological approaches that are claimed to focus exclusively on pitches, harmonies, and formal structures. Sometimes, there is a tendency for mystification not only at the side of music business and fans, but even among academics who tend to neglect their critical attitude against all kinds of myths and ideologies when it comes to sound, tone or timbre. Admittedly, these are difficult topics that touch on fields such as acoustics, psychoacoustics, and the psychology of perception - fields of knowledge that altogether lie at the border or completely outside of the competences of most popular music researchers. However, during the last two or 
three decades several interesting approaches have been developed in popular music research that encompass various phenomena of timbre, tone and sound. The main merit of the volume The Relentless Pursuit of Tone. Timbre in Popular Music is to bring together many of those approaches between two covers of a book. The fifteen case studies by seminal researchers present a kaleidoscope of thrilling phenomena related to the history and presence of popular music as well as fifteen unique approaches to investigate and understand timbre and tone.

2 In the introduction the editors propose to use the term 'timbre' for the physical and perceptual dimension of sound - what could be measured or at least empirically described - while 'tone' points at its cultural or symbolic meaning that is open to interpretation and critique. Many contributors put their emphasis on this interpretative and critical approach to sound discourses and ideologies in various genres of popular music - and as it is shown in the introduction by using the example of the marketing of guitar technology and guitar sounds: there are manifold myths and ideologies at work. The strengths of many contributions lie not only in this critical interpretation but in an empirical foundation of their critique regarding the acoustics and perception of timbre. Additionally, the reader is provided with profound and valuable information on the history of certain sound devices and sound discourses, e.g., on the acoustics of bass reflex boxes (by Robert Fink, see below), the 'twang factor' in country music (Jocelyn R. Neal), the history of guitar synthesizers (Steve Waksman) or studio reverb applications (Paul Théberge), or on classical orchestration in luxurious popular music ("luxe pop") and its interconnections to certain stereotypes within the history of film and popular culture rather than to classical European music (John Howland). Other contributions discuss the US discourse on an alleged democratization of music through recordings in the 1950s (Albin J. Zak III), the aesthetics of live performances vs. studio recordings in the early Californian rock scene (Jan Butler) or heavily distorted, 'brutal' or 'evil' timbres in death metal (Zachary Wallmark). Last but not least, in his stimulating afterword Simon Frith reflects on some basic musicological concepts such as 'musical material' and musical instrument, 'musical work' and music as collaborative action. While some authors take up studies on topics they already elaborated elsewhere, most of the contributions present original research. The volume is organized in four sections that strongly overlap: genre, voice, instrument and production. Moreover, there is further material available on the publisher's website, mainly audio files but some charts and further sources, too.

3 The first and last chapters could be read as conceptual brackets for the whole volume. In her study of the 1990s rave scene in the Bay Area, Cornelia Fales points at what she calls "the paradox of timbre": in an ecological view, sound is the most informative of all musical parameters while at the same time most listeners are disinclined "to hear timbre as an ongoing, structurally and affectively salient musical parameter with the same clarity as that with which they hear the parameters of pitch, loudness, or duration" (p. 24). While our conscious attention is dedicated to melodies, rhythms and harmonies, timbre is listened to in a rather implicit or unconscious way. Presumably, this is the reason why an adequate descriptive terminology for timbre and tone is still under work in progress. In this regard, Simon Zagorski-Thomas pursuits an ecological approach, too, complemented by the spectromorphological approach of Denis Smalley, composer of electronic music and leading theorist of acousmatic listening. According to Zagorski-Thomas, recordings tends to either present the gestures of performances with 
instruments and the musician's body, or to abstract from these real-world sound sources by using artificial, electronic sounds. However, as he convincingly demonstrates by analyzing two conventional and two electronic recordings, there are opposing effects: on the one hand, representational recordings often tends to be schematic and artificial in regard to timbre, too, by exaggerating certain sonic features, adding artificial reverb etc. - resulting in a "sonic cartoon" rather than a representation of performance reality. On the other hand, electronic music takes up manifold sound gestures we are familiar with in our listening environment. While Zagorski-Thomas' approach of an spectromorphologically informed music analysis opens up for promising new perspectives to engage with recordings of various popular music genres, Fales relies on an ethnographic approach to reconstruct in detail how listeners of electronic dance music handle the "timbre paradox" in their discourse and how they deliberately try to open up their minds for a perception of timbres.

The fleetingness and intangibility of sound always opens the doorway to mystification and ideology. In an illuminating study Robert Fink criticizes one myth widespread in the "bass culture" of reggae sound systems and electronic dance music: the myth that bass frequencies affect the listener in an immediate, somatic way. After compiling factual knowledge on low frequency perception and the technology of subwoofers, he concludes that the alleged "power deep bass appears to be our intuitive perception of how difficult it is to hear these frequencies at all" (p.112). However, not every contribution is similarly critical towards ideologies of sound. Melinda Latour rather tends to follow Carlos Santana in his pursuit for metaphysical transcendence and eternity by developing a very long sustain of his electric guitar. Griffin Woodworth ascribes a semantic of political protest to the synthesizer sounds of Stevie Wonder and Parliament - "by allowing the artist to alienate the listener momentarily from the familiar sounds that structures funk and R\&B" (p. 247), as he puts it. However, he fails to substantiate this claim with contemporary statements of artists or listeners; notwithstanding, he provides lots of valuable information on early synthesizer technologies.

5 Presumably, the human voice and singing are the most complicated and tricky areas of research on timbre. In her study of jazz singer Jimmy Scott, who had the Kallmann syndrome that prevented his voice from changing in puberty, Nina Sun Eidesheim convincingly sets out that listening to Scott allowed her to overthink the naturalized categories she had about gendered voices. In my impression, however, she fails at the task to describe the peculiarities of Scott's voice and singing style in detail. Admittedly, this is definitely not an easy task - but a main challenge of critical singing studies. Even more if it is still conceived that "the sovereignty of the voice as unassailable stronghold of the self" (p.176), as Catherine Provenzano puts it in her conclusion on the discourse around Auto-Tune technology. Moreover, as Mark C. Samples adds in regard to the legal protection of the exceptional voice of Tom Waits against misuse in advertisements, the human voice is not only an essential sonic marker for one's identity but also for one's star image or "brand persona". Again, the aesthetics of popular music are closely intertwined with its business.

6 All in all, the contributions of this groundbreaking volume are extremely inspiring. Because of its variety of topics and historical information as well as approaches and concepts, it is likely that the book will be used as a compendium to the study of tone, 
timbre and sound in popular music that, at the same time, will stimulate manifold new research.

\section{AUTHORS}

\section{MARTIN PFLEIDERER}

Martin Pfleiderer has been professor for the history of jazz and popular music at the department for musicology Weimar-Jena, music university Franz Liszt Weimar, since 2009. He studied musicology, philosophy and sociology at Giessen University and received his doctorate there in 1998 with a study on the reception of African and Asian music in jazz. From 1999 to 2005 he was a research assistant for systematic musicology at Hamburg University, where he completed his postdoctoral qualification in 2006 with a thesis on rhythm in popular music. His main research interests are the history, aesthetics and analysis of jazz and popular music, in particular regarding rhythm, singing and improvisation, the sociology of culture and computational musicology. 